\title{
A Time-Resolved Immunofluorometric Assay of Autoantibodies to Double-Stranded DNA
}

\author{
Gertjan van der Sluijs Veer ${ }^{1}$ and Hein J. Bernelot Moens ${ }^{2}$ \\ 1 Laboratorium \\ 2 Afdeling Reumatologie \\ Medisch Spectrum Twente, Enschede, The Netherlands
}

Summary: A time-resolved immunofluorometric assay (TRIFMA) of autoantibodies to double-stranded DNA (dsDNA) is described. Biotinylated DNA was bound to the polystyrene solid phase coated with streptavidin. $F\left(a b^{\prime}\right)_{2}$ fragments from antibodies raised in rabbits to human IgG were labelled with $\mathrm{Eu}^{3+}$, and used in the assay to label the bound autoantibodies to dsDNA. The measuring range covers three decades. The proposed assay has good analytical properties.

For calibration the First International Standard for antibodies to double-stranded DNA Wo/80 was used. The 97.5th percentile in normal persons is $20 \mathrm{kIU} / \mathrm{l}$. Comparison of the TRIFMA and the Farr-assay in the analysis of 56 sera from 20 patients with systemic lupus erythematosus or lupus-like disease, 13 with other autoimmune diseases, and 10 blood-bank donors indicates a high degree of concordance (Kendall's $\tau=0.56, p<0.001$ ).

Further evaluation in 102 patients with systemic lupus erythematosus, lupus-like disease and other autoimmune diseases shows that sensitivity for active classical systemic lupus erythematosus is adequate, and specificity is excellent.

\section{Introduction}

The measurement of antibodies with reactivity to double-stranded DNA (dsDNA) is important for establishing the diagnosis of systemic lupus erythematosus and in monitoring the disease $(1,2)$.

Many techniques have been developed for detection and estimation of autoantibodies to dsDNA. The most commonly used today being:

1. indirect immunofluorescence on the kinetoplast of Crithidia luciliae,

2. precipitation of the complexes formed with radiolabelled DNA (e.g. the Farr-assay), and

3. the enzyme-linked immunosorbent assay (ELISA) (3).

In general the comparability between the techniques is poor, even when the same reference preparation is used as a 'standard'. This is caused by the polyclonal nature of the autoantibodies, which can be of different avidity and isotype, both in an individual as well as in the reference preparation. Various methods have different sensitivities for various parts of the spectrum of antibodies present. All methods lack analytical specificity (4). In the Crithidia-test, anti-histone antibodies can cause false-positive results (5). A further drawback of this test is its semiquantitative and subjective interpretation. Dis- advantages of the Farr-assay are the limited measuring range, the non-linearity (6), and the use of radioactivity.

In the conventional ELISA the precoating of the solid phase, e.g. with protamine sulphate, necessary to make DNA-antigen bind to it, causes $10-20 \%$ of the positive responses to be false by binding a variety of protein complexes $(3,7,8)$. A different approach was therefore suggested by Emlen et al.: dsDNA was biotinylated by a photochemical process and bound to a streptavidincoated solid phase (7). This method has been claimed to have a better clinical specificity than the classical ELISA $(7,8)$. Unfortunately, patient-dependent non-specific binding has been described in this system as well, the nature of which is unknown so far $(3,7)$. They necessitate the subtraction of blanks for each sample.

In our laboratory the technique of the time-resolved immunofluorometric assay (TRIFMA) (9), as used in the Delfia $^{\mathrm{TM}}$ system (Wallac, Turku, Finland), shows good precision, an extended measuring range in comparison with the corresponding ELISAs, and good possibilities for automation (10).

It was decided to combine the advantages of the TRIFMA with the biotin-streptavidin technique for binding the dsDNA to the plate. Because it is known that the anti-dsDNA autoantibodies of the isotype $\operatorname{IgG}$ are clinically the most useful $(4,7)$, it was decided to 
focus on an anti-IgG label. Finally, the clinical significance and usefulness of the TRIFMA were evaluated in sera from systemic lupus erythematosus patients, other patients and controls.

\section{Materials and Methods}

\section{Reagents}

TRIS-buffer: $0.15 \mathrm{~mol} / \mathrm{l} \mathrm{NaCl}, 0.02 \mathrm{~mol} / 1$ TRIS, $\mathrm{pH} 7.8,0.8$ $\mathrm{mmol} / \mathrm{l} \mathrm{NaN}_{3}$.

Washing buffer: $0.2 \mathrm{ml}$ Tween-20 ${ }^{\mathrm{TM}}$ (Merck, Darmstadt, Germany) was added to 11 TRIS-buffer.

Assay buffer: $5 \mathrm{~g} /$ bovine albumin (Sigma, St. Louis MO, USA Product No. A 9647) in washing buffer and filtered through paper (Machery-Nagel, Düren, Germany) before use.

\section{Antigen}

Two DNA preparations were tested:

1. plasmid double-stranded DNA from $E$. coli $\left(2.3 \times 10^{3}\right.$ bases $)$, free from single stranded DNA and RNA, $>90 \%$ supercoiled (donation from Amsterdam Medical Centre, The Netherlands)

2. plasmid pBR322-(1) (Life Technologies, Breda, The Netherlands).

Photobiotin (N-(4-azido-2-nitrophenyl)-N'-(3-biotinylaminopropyl)-N'-methyl-1,3-propane-diamine acetate) (Sigma, St Louis MO, USA, Product No. A 1935) was used for DNA biotinylation.

Biotinylation of DNA was carried out following the procedure described by Forster et al. (11), slightly modified. In short: a mixture of equal volumes of DNA $(0.5 \mathrm{~g} / \mathrm{l})$ and Photobiotin $(1 \mathrm{~g} / \mathrm{l})$ was irradiated in a polypropylene cup for $20 \mathrm{~min}$ at a distance of $10 \mathrm{~cm}$, under a glass plate (Mercury discharge lamp: type HPLR-N $400 \mathrm{~W}$, Philips, Eindhoven, The Netherlands). Cooling was achieved by a fan. Excess of photobiotin was removed by butanol-2 extraction. The biotinylated DNA was precipitated with ammonium acetate and ethanol for $15 \mathrm{~min}$ at $-78^{\circ} \mathrm{C}$. After centrifugation $(10 \mathrm{~min}$, $10000 \mathrm{~g}$ ) and removal of the supernatant, the pellet was dried in the air and dissolved in a buffer (TRIS $10 \mathrm{mmol} / \mathrm{l}$, EDTA $1 \mathrm{mmol} / \mathrm{l}$, $\mathrm{pH} 7.5$ ) to a concentration of approximately $100 \mathrm{mg} / \mathrm{l}$.

Emlen et al. and Hylkema have demonstrated that this procedure does not affect the double strand character of the DNA $(7,8)$.

The solution was stored at $4{ }^{\circ} \mathrm{C}$. The degree of biotinylation was estimated by photometry from the absorbance quotient of $A_{260}$ (DNA) and $\mathrm{A}_{473}$ (Biotin). Before use the solution was diluted to $1 \mathrm{mg} / \mathrm{l}$ in TRIS-buffer.

\section{Solid phase}

Preparation of the microtitre plates (polystyrene Maxisorp ${ }^{\mathrm{TM}}$ (Nunc, Roskilde, Denmark)): plates were coated by overnight incubation at $4^{\circ} \mathrm{C}$ with $100 \mu l$ streptavidin (Sigma, St Louis MO, USA) ( $5 \mathrm{mg} / \mathrm{l}$ in TRIS-buffer) per well. Subsequently the plates were washed once with washing buffer and the excess of fluid was removed. To each well $100 \mu \mathrm{l}$ biotinylated DNA solution was added, followed by incubation for $2 \mathrm{~h}$ at room temperature. Plates were washed six times with washing buffer.

\section{Tracer}

$\mathrm{F}\left(\mathrm{ab} \mathrm{b}_{2}\right)_{2}$ fragments from antibodies raised in rabbits to human IgG (Dako A/S, Glostrup, Denmark) were labelled with $\mathrm{Eu}^{3+}$, using labelling reagent (Wallac Oy, Turku, Finland), containing N-1-( $p$ isothiocyanatobenzyl)diethylene-triamine- $\mathrm{N}^{1}, \mathrm{~N}^{2}, \mathrm{~N}^{3}, \mathrm{~N}^{3}$-tetraacetate. The procedure and the method for estimating the labelling index are described elsewhere (12).

A labelled antibody solution of $1.4 \mathrm{~g} / 1$ with a labelling index of approximately $7 \mathrm{~mol}$ europium per mol antibody was obtained.
This stock was stored at $-20^{\circ} \mathrm{C}$. The shelf life under this condition, in the presence of $1 \mathrm{~g} / \mathrm{l}$ bovine albumin as a stabilizer, was at least one year. This preparation was diluted before use to a final antibody concentration of $2.5 \mathrm{mg} / \mathrm{l}$ in assay buffer. The reagent was filtered before use through a $0.2 \mu \mathrm{m}$ filter FP030/30 (Schleicher \& Schuell, Dassel, Germany).

\section{Subjects and samples}

\section{Calibrators}

For the calibration the First International Standard for antibodies to double-stranded DNA Wo/80 (Central Laboratory of the Netherlands Red Cross Blood Transfusion Service (CLB), Amsterdam, The Netherlands), which contains $100 \mathrm{IU} /$ vial by definition, was used (13). This preparation was reconstituted in distilled water $(0.5$ $\mathrm{ml} / \mathrm{vial}$ ) and further diluted in assay buffer to a set of calibrating solutions ranging from 0.1 to $20 \mathrm{kIU} / \mathrm{l}$, corresponding to 5 to 1000 $\mathrm{kIU} / \mathrm{l}$ under assay conditions.

As a secondary calibrator a serum from patient $\mathrm{X}$, suffering from classical non-renal systemic lupus erythematosus was selected, dilutions of which showed a good parallelism with the Wo/80 (fig. 1). The autoantibody to dsDNA concentration was estimated as $342 \mathrm{kIU} / \mathrm{l}$ in the TRIFMA.

The recently introduced Dutch Reference Preparation for autoantibodies to dsDNA (Relares, CLB, Amsterdam, The Netherlands) was also tested for its use as a secondary calibrator.

\section{Control samples}

For the estimation of the between-run precision, three pools of patient sera were prepared with respectively low (19 kIU/ $)$, intermediate (40 kIU/l) and high (137 kIU/l) concentrations of autoantibodies to dsDNA. Freeze-dried aliquots were stored at $-80^{\circ} \mathrm{C}$, and reconstituted before use.

\section{Sera}

For the comparison between the TRIFMA, the Crithidia-test and the Farr-assay, and for the other studies described, 56 sera were selected from 20 patients with a clinical diagnosis of systemic lupus erythematosus ( 4 with and 7 without renal involvement, 18 sera) or lupus-like disease ( 9 patients, 15 sera). These patients fulfilled at least 4 (systemic lupus erythematosus) or 3 (lupus-like disease) criteria for systemic lupus erythematosus other than the presence of anti-DNA antibodies (1) (tab. 1). Also 13 sera were obtained from patients with other autoimmune diseases (rheumatoid arthritis: 6, primary anti-phospholipid syndrome: 2 , other: 5), randomly selected from the rheumatological outpatient clinic ( $n=13,4 \hat{\delta}, 9$ \%, age (range) $25-80 \mathrm{a}$ ), and 10 from blood-bank donors.



Fig. 1 Parallelism of primary calibrator Wo/80 (०-), the serum of patient X (used as secondary calibrator) ( $\square---)$ ), and Dutch Reference Preparation for autoantibodies to dsDNA $(\nabla \cdots)$. 
Sera from blood-bank donors $(n=66,39 \delta, 27 \%$, age (mean $\pm S D) 42 \pm 12$ a) were used for establishing the reference interval. To investigate specificity and interference, 18 sera from patients with rheumatoid arthritis (rheumatoid factor $(\operatorname{lgM})>10$ times the upper limit of the reference interval) were tested.

All sera were stored at $-20^{\circ} \mathrm{C}$ before analysis.

After finishing these studies, we evaluated the performance of the TRIFMA under routine conditions: the results of all tests for autoantibodies to dsDNA requested by all the rheumatologists during the year 1995 (in 211 sera from 102 patients) werc grouped according to their diagnosis and their content of autoantibodies to dsDNA (TRIFMA).

\section{Methods}

\section{The proposed TRIFMA}

Immediately after preparing the solid phase, the assay procedurc was performed at room temperature and consisted of

1) incubation for 2 hours of the coated microtitre well with $100 \mu$ l of the respective calibrator dilutions, samples (diluted $1: 50$ in assay buffer) or assay buffer (reagent blank) in duplicate,

2) six wash steps with washing buffer,

3) incubation with $100 \mu l$ of the labelled antibody,

4) six wash steps with washing buffer,

5) incubation for 15 min with $200 \mu l$ of the enhancement solution (Pharmacia, Turku, Finland): containing $6.8 \mathrm{mmol} / 1$ potassium hydrogen phthalate, $100 \mathrm{mmol} / 1$ acetic acid, $50 \mu \mathrm{mol} / 1$ tri-n-octylphosphine oxide, $15 \mu \mathrm{mol} / \mathrm{l} 2$-naphthoyl-trifluoro-acetone and $1 \mathrm{~g} / 1$ Triton $X-100, \mathrm{pH} \mathrm{3.2,} \mathrm{followed} \mathrm{by} \mathrm{standing} \mathrm{for} 10 \mathrm{~min}$,

6) measurement of the time-resolved fluorescence with the Arcus Fluorometer, type 1232 (Wallac Oy, Turku, Finland).

All incubation steps were performed while shaking the microtitre plates on a Delfia Plateshaker 1296-001 (Wallac, Turku, Finland) in the position 'slow' (frequency: $950 \mathrm{~min}^{-1}$ ). To obtain the net signal, the blank signal of each calibrator or sample, measured by the same procedure but omitting the coating with biotinylated DNA, was subtracted from the signal of each calibrator resp. sample.

\section{Other methods}

For method comparison the autoantibody to dsDNA was also measured

1. by the Farr-assay (anti-DNA, Diagnostic Products Corporation, Los Angeles CA, USA), according to the instructions of the manufacturer. However, the Wo/80 was used as the calibrator and not the standards provided with the kit. For results exceeding the measuring range (i.e. $>50 \mathrm{kIU} / \mathrm{l}$ ) the result was calculated by an extrapolation of concentrations measured in several dilutions in a normal (autoantibody to dsDNA negative) serum. Reference value: $<3 \mathrm{kJU} / \mathrm{l}$.

2. by the indirect immunofluorescence test on Crithidia luciliae (anti human IgG) (Immunoconcepts, Sacramento CA, USA). Results were scored as negative, weak positive or positive. Reference value: negative.

\section{Statistics}

The statistical comparison of methods was performed according to Passing \& Bablok (14) and by Kendall's rank correlation test.

\section{Results \\ Reagent preparation}

\section{Antigen}

The mean biotinylation index of the DNA was 1 molecule biotin/18 base pairs, range $9-27(n=5)$. There was no substantial difference in behaviour between the two DNA preparations tested in the TRIFMA.

\section{Label}

The mean labelling index $(\mathrm{n}=3)$ was $7 \mathrm{~mol} \mathrm{Eu}^{3+} / \mathrm{mol}$ IgG $\left(F\left(a b^{\prime}\right)_{2}\right)$, (range $\left.5-9 \mathrm{~mol} / \mathrm{mol}\right)$.

\section{Analytical evaluation}

\section{Assay characteristics}

The calibration curve (Wo/80) was linear from 5 to 500 $\mathrm{kIU} / \mathrm{l}$, with a small deflection for the higher values. A typical standard curve is shown in figure 2.

The Dutch Reference Preparation (Relares, CLB, Amsterdam, The Netherlands) was tested. It was found to contain $300 \mathrm{kIU} / \mathrm{l}$ if assayed as a patient's serum in the TRIFMA, i.e. in a $1: 50$ dilution. Since a lack of parallelism (fig. 1) between the two preparations exists, each dilution of the Dutch Reference Preparation would have to be calibrated separately on the Wo/80 for use in a calibration curve in the TRIFMA. In addition we tested dilutions of more sera from systemic lupus erythematosus patients, all showing a parallelism with the Wo/80 and our secondary calibrator (patient X's serum), but not with the Dutch Reference Preparation.

Linearity was good when tested in the following way: two sera with high autoantibody to dsDNA concentration (150 and $650 \mathrm{kIU} / \mathrm{l}$ respectively) were diluted serially with

a) the assay buffer

b) a serum with a low concentration of antibodies to dsDNA

c) a serum with a low concentration of autoantibodies to dsDNA and a high concentration of rheumatoid factor. These dilutions were assayed in the same way as samples.

The lower detection limit was determined by replicate analysis $(n=12)$ of the assay buffer. It was defined as

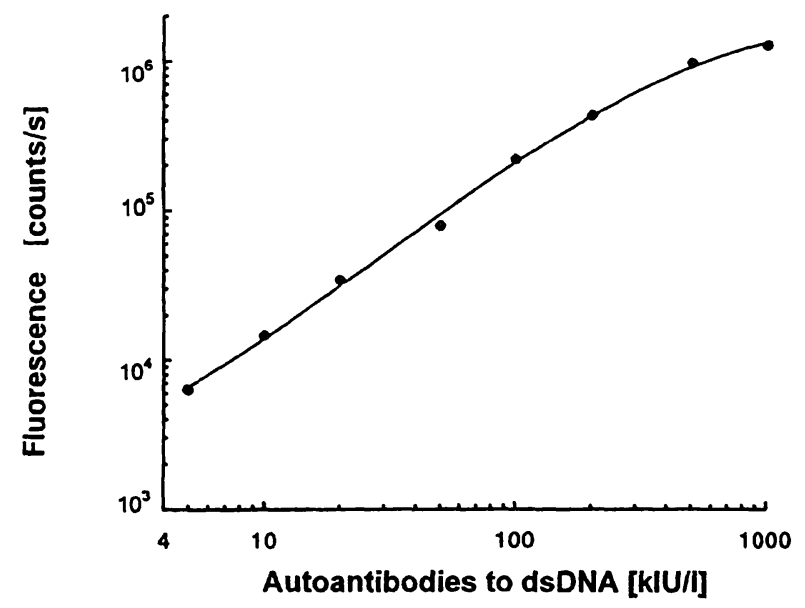

Fig. 2 A typical standard curve. 
the concentration of autoantibodies to dsDNA corresponding to the mean $+3 \mathrm{SD}$ response of the assay buffer. The limit was found to be $1.7 \mathrm{kIU} / \mathrm{l}$.

Within-run precision was estimated by measuring sera with different autoantibody to dsDNA concentration in replicate $(n=20)$. The autoantibodies to dsDNA can be measured at a precision of $<10 \%$ in the range 5 to $20 \mathrm{kIU} / \mathrm{l}$, and $<6 \%$ in the range 20 to $1000 \mathrm{kIU} / \mathrm{l}$.

The between-run precision was estimated by measuring three pools of patient sera in duplicate in twenty runs. It was found to be $<12 \%$.

The correlation between the Farr-assay and the TRIFMA was calculated by Kendall's test: Kendall's $\tau=0.56$, $\mathrm{p}<0.001$. Results of the regression analysis are shown in figure 3.

The relation between the proposed TRIFMA and the indirect immunofluorescence on Crithidia luciliae is shown in figure 4.

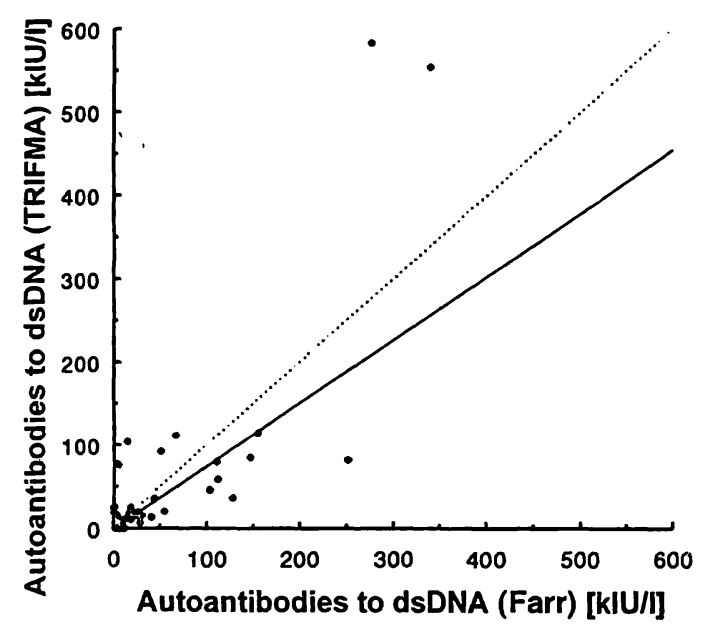

Fig. 3 Regression between concentrations of autoantibodies to dsDNA measured by the Farr-assay (x) and by TRIFMA (y) for 56 sera. The regression line (according to Passing \& Bablok (14)) was $y=0.75 x-1.5$. Confidence intervals: slope: 0.59 to 1.25 , intercept: -2.5 to -0.05 . Line of identity $(\cdots \cdots)$.

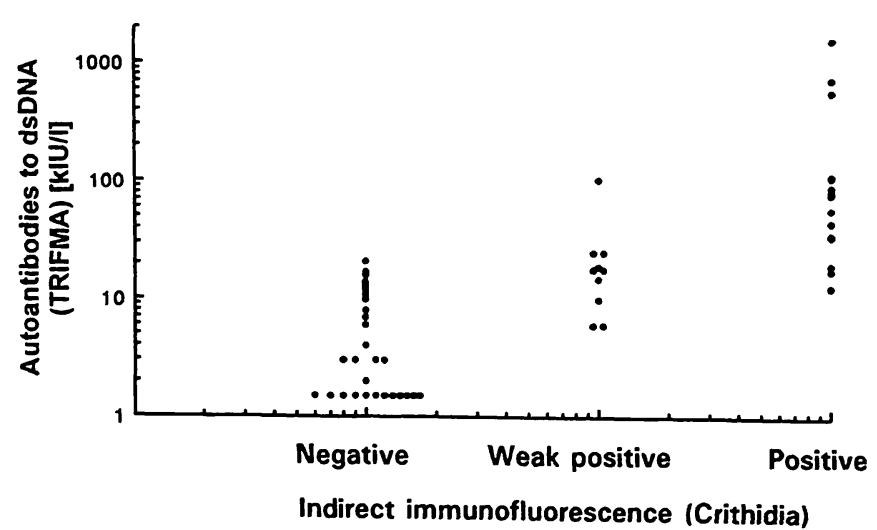

Fig. 4 Relation between concentrations of autoantibodies to dsDNA measured by indirect immunofluorescence on Crithidia luciliae and by TRIFMA.

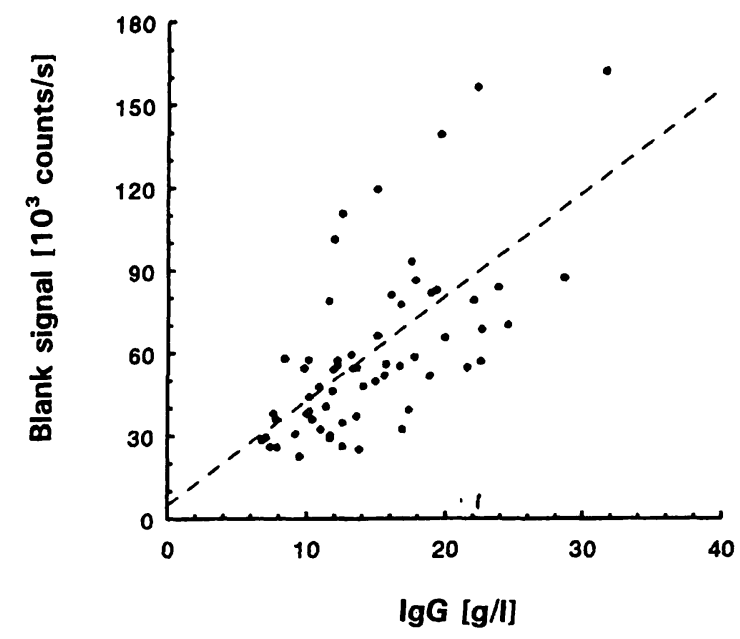

Fig. 5 Correlation of TRIFMA blank signal with total IgG concentration in 56 serum samples.

\section{Non-specific effects}

The influence of blocking the plates with albumin, a common procedure in immuno assays, was examined. There was only a small difference in blanks of plates with and without an albumin blocking step, provided that the assay-buffer contained albumin. Since precision decreased with blocking, this step was abandoned.

The system shows non-specific binding, which is patient-dependent and even occurs in some normal persons. Therefore, to prevent false positive results, blank signals must be taken into account.

There was a significant correlation between the sample blank signal and its total $\operatorname{IgG}(r=0.64)$. The regression is shown in figure 5. Hence an attempt was made to suppress the supposed non-specific binding of IgG by adding relatively high concentrations of rabbit and goat globulins to the assay buffer: normal goat serum and normal rabbit serum (CLB, Amsterdam, The Netherlands) up to protein concentrations of $8 \mathrm{~g} / \mathrm{l}$. These attempts were not successful: the specific and non-specific signals decreased to the same degree, individual patients remaining significantly different in their blank signals.

\section{Clinical significance}

In healthy blood-bank donors $(n=66)$ the reference value was determined as $\leq 20 \mathrm{kIU} / \mathrm{l}$ (97.5 percentile).

In patients with classical systemic lupus erythematosus, the Farr-assay and TRIFMA produced comparable results (tab. 1). Discordant results were found mostly in cases with autoantibody to dsDNA concentrations close to the threshold values. The Farr results ranged between 4 and $55 \mathrm{kIU} / \mathrm{l}$, those from the TRIFMA from 0 to 20 $\mathrm{kIU} / \mathrm{l})$.

The distribution of TRIFMA results for different diagnoses in all rheumatological patients tested for autoantibodies to dsDNA in 1995 are shown in table 2. 
Tab. 1 Results of TRIFMA and Farr-assay in 3 patient groups.

\begin{tabular}{|c|c|c|c|c|}
\hline & $\begin{array}{l}\text { Number of } \\
\text { patients }\end{array}$ & Age range & $\begin{array}{l}\text { Farr and } \\
\text { TRIFMA } \\
\text { concordant }\end{array}$ & $\begin{array}{l}\text { Farr above, } \\
\text { TRIFMA within } \\
\text { reference value }\end{array}$ \\
\hline & $\delta / q$ (Sera) & (a) & Patients (Sera) & Patients (Sera) \\
\hline $\begin{array}{l}\text { Systemic lupus erythematosus } \\
\text { (renal involvement) }\end{array}$ & $0 / 4 \quad(7)$ & $21-76$ & $4(7)$ & $0(0)$ \\
\hline $\begin{array}{l}\text { Systemic lupus erythematosus } \\
\text { (non-renal) }\end{array}$ & $2 / 5(11)$ & $25-67$ & $2(2)$ & \\
\hline Lupus-like disease & $0 / 9(15)$ & $15-49$ & $6(9)$ & $3(6)$ \\
\hline
\end{tabular}

Tab. 2 Distribution of sera grouped according to clinical diagnosis and concentrations of autoantibodies to dsDNA (TRIFMA) in 102 patients from the Department of Rheumatology.

\begin{tabular}{|c|c|c|c|c|c|}
\hline \multirow[t]{2}{*}{ Diagnosis } & \multirow{2}{*}{$\begin{array}{l}\text { Number } \\
\text { of sera } \\
\text { (patients) }\end{array}$} & \multicolumn{4}{|c|}{ Number of sera containing autoantibodies to dsDNA } \\
\hline & & $\leq 20 \mathrm{kIU} / \mathrm{l}$ & $21-50 \mathrm{kJU} / \mathrm{l}$ & $51-100 \mathrm{kJU} / \mathrm{l}$ & $>100 \mathrm{kIU} / \mathrm{l}$ \\
\hline $\begin{array}{l}\text { Systemic lupus erythematosus } \\
\text { - renal }\end{array}$ & $25(5)$ & $3(12 \%)$ & $4(15 \%)$ & $14(54 \%)$ & $5(19 \%)$ \\
\hline $\begin{array}{l}\text { Systemic lupus erythematosus } \\
\text { - non-renal }\end{array}$ & $103(26)$ & $50(48 \%)$ & $26(25 \%)$ & $15(15 \%)$ & $12(12 \%)$ \\
\hline $\begin{array}{l}\text { Systemic lupus erythematosus } \\
\text { - discoid }\end{array}$ & $4(3)$ & $4(100 \%)$ & 0 & 0 & 0 \\
\hline Lupus-like disease & $5(4)$ & $4(80 \%)$ & 0 & $1(20 \%)$ & 0 \\
\hline Rheumatoid arthritis & $27(24)$ & $26(96 \%)$ & $1(4 \%)$ & 0 & 0 \\
\hline Other systemic autoimmune diseases & $13(10)$ & $13(100 \%)$ & 0 & 0 & 0 \\
\hline Other rheumatic diseases & $33(30)$ & $32(97 \%)$ & $1(3 \%)$ & 0 & 0 \\
\hline
\end{tabular}

\section{Discussion}

Current methods for measurement of autoantibodies to DNA have drawbacks, which in turn cause difficulties in clinical interpretation. The proposed TRIFMA may represent an advance by the introduction and combination of two improvements: the use of time-resolved detection of an europium label and an alternative technique for binding of the antigen to the solid phase.

The introduction of an europium label potentially extends the standard curve up to about three decades. This obviates the need for retesting sera with high concentrations of autoantibodies to dsDNA in different dilutions. Moreover this offers the possibility of measuring longitudinal series of samples without interference by different matrix effects.

Binding the DNA-antigen to the solid phase by a streptavidin-biotin bridge yields an improvement in specificity in assays for autoantibodies to dsDNA $(7,8)$.

Unfortunately the system shows non-specific binding to polystyrene, presumably of IgG, which is patient-dependent and even occurs in some normal persons, necessitating subtraction of blank measurements. From the point of view of efficiency, this is undesirable: logistically, the number of samples to be handled doubles and two types of coating have to be used. Analytically, the within-run precision deteriorates considerably, especially at low concentrations, by the statistical propagation of errors. Others have struggled with this phenomenon as we did $(3,7)$, but so far no one seems to have been successful in solving the problem of unspecific binding. The only clue we found, was a significant correlation of the blanks with total IgG in the sample. Efforts to suppress this binding specifically by adding nonimmunoreactive globulins (goat and rabbit serum) were not succesful.

Calibration in this type of assay is an illusion. This is illustrated for instance by the difference in reference values for the Farr-assay and the TRIFMA, both expressed in Wo/80 International Units. Another example is the non-parallel behaviour of the Dutch reference preparation for autoantibodies to dsDNA, in comparison with the Wo/80, using the same technique. These phenomena are of course caused by the pluriformity of the antibodies in the reference preparations as well as in individuals. Each method measures its own part of the spectrum of antibodies present in the sample. At best, an international reference preparation can yield comparability of results among centres if these use the same method. 
Even so, a strong correlation was found between the Farr-assay and TRIFMA (Kendall's $\tau=0.56$, $\mathrm{p}<0.001$ ). Some individuals showed a relatively large deviation from the calculated regression line. Emlen et al. suggested that IgM antibodies could possibly be responsible for this finding, for they are reactive in the Farr-assay but not in the TRIFMA (7). Since the presence of anti-DNA antibodies is an important criterion for the diagnosis of systemic lupus erythematosus (1), it is difficult to establish the sensitivity and specificity of a new test for this analyte. We have, therefore, divided the patients into groups based on criteria other than the presence of anti-DNA antibodies. The data in our small patient group indicate that the TRIFMA is concordant with the Farr-assay in classical systemic lupus erythematosus patients. In the case of less certain diagnostic circumstances, usually described as 'lupus-like disease', we found normal values in 5 patients who had (mildly) positive results in the Farr-assay. Although these data may be interpreted as indicative of low sensitivity, the clinical diagnosis of systemic lupus erythematosus was indeed questionable in these patients, who had been followed for 1-6 years. Therefore a higher specificity of the TRIFMA can be considered. The assumption that the new assay provides better discrimination between systemic lupus erythematosus and non-systemic lupus erythematosus needs further study in larger patient groups.

Anti-DNA testing is perhaps even more important for the follow-up of systemic lupus erythematosus patients

\section{References}

1. Tan EM, Cohen AS, Fries JS, Masi AT, McShane DJ, Rothfield NF, et al. The 1982 revised criteria for the classification of systemic lupus erythematosus. Arthritis Rheum 1982; 25:1271-7.

2. Borg EJ ter, Horst G, Hummel J, Limburg PC, Kallenberg CGM. Predictive value of rises in anti-double-stranded DNA antibody levels for disease exacerbation in systemic lupus erythematosus: a long prospective study. Arthritis Rheum 1990; 33:634-43.

3. Smeenk R. Measurement of antibodies to DNA. In: Venrooij WJ van, Maini RM, editors. Manual of biological markers of disease. Dordrecht (The Netherlands): Kluwer Academic Publishers, 1993; A8:1-12.

4. McPherson RA. Serological evaluation of renal status. Clinics in Laboratory Medicine 1993; 13(1):69-87.

5. Deng JS, Sontheimer RD, Lipscomb MF, Gilliam JN. The binding of antihistone antibodies to Crithidia luciliae kinetoplasts is growth cycle-dependent. Arthritis Rheum 1985; 28:163-8.

6. Diagnostic Products Corporation. Insert leaflet in Anti-DNAkit. Los Angeles, 1992.

7. Emlen W, Jarusiripipat P, Burdick G. A new ELISA for the detection of double-stranded DNA antibodies. J Immunol Methods 1990; 132:91-101.

8. Hylkema MN, Huygen $H$, Kramers $C$, Wal ThJ van der, Jong $\mathrm{J}$ de, Bruggen $\mathrm{MCJ}$ van, et al. Clinical evaluation of a modified ELISA, using photobiotinylated DNA, for the detection of anti-DNA antibodies. J Immunol Methods 1994; 170:93-102.
(2). Our present patient group included only a few patients in whom disease activity varied strongly during the consecutive observations. In these cases the TRIFMA paralleled the Farr-assay. The fact that a few patients followed longitudinally showed a normal TRIFMA result in periods of recovery, while the Farrassay remained marginally elevated, indicates a slightly smaller sensitivity of the former.

However, the data from the cohort of 102 patients from the Department of Rheumatology, who were routinely tested during one year for autoantibodies to dsDNA (tab. 2), demonstrate adequate sensitivity, especially for renal systemic lupus erythematosus, in combination with a high specificity.

\section{Conclusion}

The proposed time-resolved immunofluorometric assay of autoantibodies to double-stranded DNA has good analytical properties, good sensitivity and excellent specificity. Features that make the test superior to the Farrassay are an extended measuring range, better linearity and the use of a non-radioactive label. Further studies to establish the predictive value of autoantibodies to dsDNA measured are in progress.

\section{Acknowledgements}

The authors thank $\operatorname{Mr}$ A. J. F. Leemhuis and Mrs L. P. M. KipOude Grote Beverborg for their excellent technical assistance.
9. Hemmilä I. Lanthanides as probes for time-resolved fluorometric immunoassays. Scand J Clin Lab Invest 1988; 48:389-400.

10. Sluijs Veer G van der, Soons JWPH. A time-resolved fluoroimmuno assay of the IgM-rheumatoid factor. Eur J Clin Chem Clin Biochem 1992; 30:301-5.

11. Forster AC, Mclnnes JL, Skingle DC, Symons H. Non-radioactive hybridization probes prepared by the chemical labelling of DNA and RNA with a novel reagent, photobiotin. Nucleic Acids Res 1985; 13:745-61.

12. Pharmacia/Wallac Oy. Lanthanide labelling for time-resolved fluorometry. Turku (Finland), 1990.

13. Feltkamp TEW, Kirkwood TBL, Maini RN, Aarden LA. The first international standard for antibodies to double-stranded DNA. Ann Rheum Diseases 1988; 47:740-6.

14. Passing $H$, Bablok W. A new biometrical procedure for testing the equality of measurements from two different analytical methods. Application of linear regression procedures for method comparison studies in clinical chemistry, Part I. J Clin Chem Clin Biochem 1983; 21:709-20.

\section{Received February 9/July 3, 1996}

Corresponding author: Gertjan van der Sluijs Veer, Laboratorium, Medisch Spectrum Twente, Postbus 50 000, NL-7500 KA Enschede, The Netherlands 